Arab World English Journal (AWEJ) Volume 12. Number3 September 2021

DOI: https://dx.doi.org/10.24093/awej/vol12no3.1

Pp. 3-15

\title{
EFL Students' Awareness of Culture-Specific Words and Concepts: The Challenges and Opportunities for Students in a Saudi Undergraduate English Program
}

\author{
Abdullah Abdulrahman Bin Towairesh \\ Department of English Language and Translation, College of Languages and Translation \\ King Saud University, Riyadh, Saudi Arabia \\ Email: abintowairesh@KSU.EDU.SA
}

Received: 4/3/2021

Accepted: 8/7/2021

Published: 9/24/2021

\section{Abstract}

Cultural knowledge is an integral part of the language teaching process in EFL situations. The difficulties facing students in this area have negatively affected their ability to communicate successfully and translate accurately. Nonetheless, the debate over the significance of involving cultural aspects in the language classroom has continued in the local Saudi context. The language weaknesses resulting from the lack of sufficient cultural perspective can also be observed and confirmed in this region. Students' understanding of culture-specific words and concepts is the area that is affected the most when a disconnection occurs between language teaching and cultural knowledge. Thus, in this paper, the researcher examines the impact of this disconnection by outlining the extent to which cultural knowledge is incorporated into EFL language courses. This study also focuses on documenting the language use examples that illustrate the difficulties faced by students in this regard, which is an aspect that is missing from several previous studies in the local context. The data examined in this study were collected through open-ended questionnaires and organizing focus group discussions. The analysis of the results reveals that the cultural component of language teaching is not satisfactory for the English major students surveyed in this study. The research participants also described the kind of cultural knowledge missing from their curriculum and the specific areas affected by that. The study concludes with several suggested solutions that focus on the resources available to Saudi students (and other students in the same circumstances) and on utilizing the most recent developments in online education in the past two years.

Keywords: awareness, challenges and opportunities, language and culture, idiomatic expressions, Saudi EFL undergraduate programs

Cite as: Bin Towairesh, A. A. (2021). EFL Students' Awareness of Culture-Specific Words and Concepts: The Challenges and Opportunities for Students in a Saudi Undergraduate English Program . Arab World English Journal, 12 (3) . 3-15.

DOI: https://dx.doi.org/10.24093/awej/vol12no3.1 


\section{Introduction}

In the EFL classroom, culture cannot be separated from language in any way, and any attempt to teach a foreign language or to complete a translation task in disconnection from culture is destined to fail. In fact, neglecting the cultural aspects of a language can be a significant hurdle in the path of teaching it (Singhal, 1997). Similarly, misunderstanding cultural concepts is described as one of the most significant obstacles in achieving accurate and effective translations (Newmark, 2010). Thus, for EFL/translation students, it is imperative that they understand the connection between language and culture and realize the impact of this connection on the quality of their language learning efforts and on the accuracy of their translation work.

The process of including culture in the foreign language classroom has been examined extensively in several publications in the past, including by Choudhury (2013), Dema and Möller (2012), and Kramsch (1993). These authors, and others, have emphasized the centrality of connecting language to culture in the classroom and have outlined the ramifications of failing to do so. In the Saudi context, the English language plays an increasingly important role in the economy and the educational system of the country. As part of Kachru's "expanding circle" (1992), Saudi society places great emphasis on learning English as a foreign language and assigns prestige and high status to those fluent in it. However, the opinions on incorporating culture in the process of teaching English have not always been in unison. Alseghayer (2009) talked about certain voices in society that once called for the "purification" of English language curricula from the "influence" of foreign culture and for presenting the content in a purely local mold. That said, in academia, the calls for supporting the inclusion of culture in language teaching in Saudi Arabia have remained constant, and the arguments for these calls have relied on scholarly research and well-examined theories on second language learning. Examples of some of the studies that have examined this topic in the local context include Aldawood and Almeshari (2019), Alsamani (2014), and Mekheimer and Aldosari (2011).

In general, Saudi youths closely follow certain aspects of the English language culture, specifically those connected to entertainment and soccer (football). University students are no exception in this regard, and undergraduate EFL students' exposure to the English language culture is mainly focused on these aspects. Thus, it would not be surprising to meet students who have knowledge of some of the cultural concepts featured in Western entertainment delivered in English. The problem, however, is that, in many cases, this knowledge can be viewed as limited to the most recurrent cultural themes in this type of entertainment (superficial knowledge) and can also be described as lacking the serious (formal) side of the culture. For example, in the researcher's experience, many EFL students have struggled to understand many words and concepts connected to the more serious aspects of the English language culture, specifically in the fields of politics, intellectual writings, and the local urban culture of cities in the Englishspeaking world. Many students can also be described as having extremely minimal knowledge of the culture connected to sports other than soccer, even though these sports represent an integral part of the broader culture of English-speaking societies. This is manifested most clearly in the prevalence of sports metaphors and the significance of discussing sports and sporting events in the English language culture.

As an English language instructor teaching several EFL and translation courses for more than 12 years, the researcher has observed several areas wherein students have struggled with regards 
to recognizing significant cultural aspects of the foreign language they are learning (and translating from), resulting in comprehension and communication difficulties and translation mistakes. Thus, the aim of this paper is to examine the current state of involving culture in language teaching in an EFL/translation university program. The specific target of this research is the students at King Saud University's (KSU) English language program offered by the College of Languages and Translation (COLT). The goal is to identify the extent of the difficulties resulting from learning a foreign language in a setting that does not provide sufficient cultural context, which in many cases may lead to weaknesses in the communicative competence of students and to several accuracy issues in their translation performance.

The next step is to discuss examples of the most common communication and translation errors caused by these weaknesses in the case of Saudi undergraduate students. Reviewing these mistakes will help in outlining the scope of the problem for students in this area. It will also illustrate the kind of issues students face, given their specific situation, being both EFL students and translation trainees at the same time.

Ultimately, the aim is to suggest solutions and present recommendations based on the collected data and in light of the most effective methods and techniques examined in previous research on this topic. It is hoped that the suggested solutions and recommendations can be applied to other students around the world facing the same circumstances with regard to the lack of intercultural knowledge in situations involving teaching English as a foreign language.

In this study, the goal is to examine the impact of the disconnection between language and culture by outlining the extent to which cultural knowledge is missing from Saudi EFL language classes at the university level.

\section{Literature review}

What drives many language programs and instructors to attempt to teach a foreign language without its cultural context is either the fear that such context would clash with the local traditions and norms or the desire to emphasize the students' own cultural principles. Shamail (2015) stated that in situations where the focus is heavily on the local culture and where the cultural aspects of the foreign language are excluded, the result might be a reduced communicative competence for students. This could also be combined with several difficulties for language learners in understanding the "globalized world of English" (Shamail, 2015, p. 21). The author also discussed the possibility of creating teaching content that connects both cultures and that functions as a bridge between the learner's own world and that of the target language. This suggestion is relevant in the cases where maintaining a strong presence of the local culture in the foreign language curriculum is considered a vital priority. The benefits of teaching culture in the EFL classroom go beyond the goal of broadening the learners' cultural perspective to cover aspects closely connected to the language learning process. For example, Shamail (2015) suggested that students can be driven by a sense of curiosity to explore the target language culture in a way that can enhance their mastery of the foreign language.

When students are faced with situations that exclude culture from language teaching, they might resort to other resources to compensate for this deficiency. These include, for example, the use of dictionaries to translate the culture-specific terms that students come across during casual 
conversations, in the classroom, or while performing their language learning tasks. Goodwin (2013) examined this situation and indicated that this method might not be of much help to students in the cases where the literal translation misrepresents the actual meaning of words that have cultural connotations.

The type of culture to be introduced into the EFL teaching process and the methods of presenting cultural elements have been two highly prominent themes in the discussions focusing on intercultural competence in previous studies. Lavrenteva and Orland-Barak (2020) indicated that the teachers in their research "took advantage of real-life resources such as electronic media, literature, documentaries, history, and movies" to achieve the goals of teaching culture in the EFL classroom (p. 28). The use of literature, in particular, as the main resource in this process has been discussed extensively in a number of studies, including Bagui and Adder (2020) in Algeria and Mekheimer and Aldosari (2011) in Saudi Arabia. In the first study, this technique faced several hurdles associated with the levels of cultural awareness of students. Specifically, the researchers stated that students in their study were "not culturally competent enough to avoid intercultural clash within various sessions of literature" (Bagui \& Adder, 2020, p. 92). In the second study, however, Mekheimer and Aldosari (2011) reported that the Saudi students who responded to their questionnaire showed great enthusiasm for reading literary works as part of their EFL learning experience. The authors also indicated that Saudi students "already recognize the important role that literature can play in culture learning in EFL classes." In their data, the participating students emphasized the fact that "novels and stories are extensively loaded with culture" and expressed their desire to "study many of these courses across the language curriculum (p. 12)."

In addition to literature, Hamza (2018) discussed other resources that can be utilized in the process of introducing culture to EFL students, including the use of newspapers and magazines, websites, TV shows, films, and videos. He added that encouraging language learners to read newspapers offers them an excellent opportunity to familiarize themselves with multiple aspects of the foreign language's culture. These opportunities can be found in the different sections of the newspaper, such as advertisements, editorials, sports pages, and comic strips. Hamza (2018), however, argued that, in some instances, the language difficulty in newspapers might be discouraging to some students, which requires teachers to provide support to facilitate the use of this resource. As for the use of videos, the author discussed a method in this regard that involves students watching videos, then writing down lists of things that are different in their culture from what they are in the videos. He argued that this exercise allows students to remember the language aspects and to identify intercultural differences.

An essential theme in the discussions on involving culture in the EFL classroom is the kind of cultural knowledge that should be introduced to language learners. In the majority of EFL textbooks, the cultural elements featured in their content is strongly connected to the societies of the countries in Kashru's (1992) inner circle, such as the United States, the United Kingdom, Australia, and New Zealand. Several researchers, however, have criticized this focus on the cultural knowledge of these societies and have called for a more comprehensive understanding of the concept of English language culture. For example, Jeeyoung et al. (2011) reviewed "seven series of internationally distributed ELT textbooks" (p. 253) to examine the kind of culture featured in these resources. The authors reported that the cultural elements of inner circle 
societies dominated the content of these textbooks in a way that does not reflect the global nature of the English language in today's world. Baker (2012) reiterated the same notions in his paper, stating that "the use of English as the global lingua franca highlights the need for an understanding of cultural contexts and communicative practices to successfully communicate across diverse cultures" (p. 69). He added that teachers should consider going beyond teaching fixed cultural contexts in connection to the English language to allow their students to reach the level of successful communication.

Many scholars have also focused on teachers' attitudes toward incorporating culture into the EFL classroom. Bayyurt (2006) surveyed a number of English language schoolteachers to examine their perspective on introducing cultural aspects into their classrooms. Given the status of English as an international language, the participants in this study highlighted the importance of "of referring to an 'international culture' with special emphasis on English speaking Anglo American cultures, as well as the learners' local culture" (p. 233). In another study focusing on university-level students and teachers, Yeşil and Demiröz (2017) confirmed these positive attitudes toward offering culturally contextualized language learning. The teachers in this study reiterated the same understanding of the importance of connecting the foreign language to its culture. They, however, stated that not having enough time in the lectures to introduce cultural knowledge was one of the most significant obstacles in this regard. As for their students' academic achievement and motivation, the participants indicated that the practice of target culture teaching has had "a positive and motivating impact on their proficiency level of English" (p. 79).

Other researchers have analyzed the ultimate goal of teaching culture in EFL situations, with a particular focus on intercultural understanding, tolerance, and empathy. For example, in a study focused on grades seven to nine teachers of English, the objective was to assess their understanding of the concept of "culture" in the foreign language classroom. In this study, the teachers agreed that the goal of teaching culture is to equip students with the skills that would allow them to engage in intercultural encounters successfully. They also highlighted the idea that respecting the differences between cultures is a general goal that should not be exclusively connected to situations involving English-speaking countries (Larzén-Östermark, 2008).

All the studies above have contributed substantially to our understanding of intercultural knowledge in the EFL classroom. However, certain aspects of this field are yet to be explored sufficiently, specifically, those connected to tertiary-level Arabic-speaking students in situations involving both communication and translation. Thus, this paper aims to examine the current state of teaching culture in EFL university classrooms with students enrolled in language skills, linguistics, and translation courses. The objective is to identify the level of disconnection between language and culture in these courses and to illustrate this situation with language-use examples that highlight the negative impact of excluding the cultural context from certain aspects of language. The lack of real-life instances of misunderstanding cultural concepts and culture-specific words is significant in many studies that have discussed this issue. Thus, it is hoped that this study can be one step in that direction and that it can be the basis for future comparative studies to measure the effects of this situation on EFL students in other societies around the world. 


\section{Methods}

To achieve the goals of this study, the researcher adopted two data collection methods, which are open-ended questionnaires and focus groups.

\section{Participants}

The questionnaires were sent out to 107 EFL undergraduate students enrolled in the English language program at King Saud University's College of Languages and Translation (COLT, KSU). The focus group sessions included 12 participants from the same program divided into two groups. All the participants were in the third and fourth year of the four-year undergraduate English program. Students usually enroll in language skills courses in the first three semesters of that program and then continue to study linguistics and translation courses.

\section{Instruments}

The choice of an open-ended questionnaire was made to allow participants to elaborate on the selected issues without being limited to the answers that can be given in a multiple-choice format. This gave participants more freedom to describe the challenges, provide examples, and suggest solutions. The questionnaire consisted of four main open-ended questions covering the main issues discussed in this study (with prompts to explain and discuss). These included (1) students' perspective on the disconnection between language and culture in their program, (2) language-use examples illustrating the results of this disconnection, (3) students' external resources utilized in this regard, and (4) students' opinions on the possible solutions that can be provided by the college to remedy this situation.

The goal of organizing the focus groups was to provide information that could corroborate the data collected from the questionnaires and to give students a venue in which they could express their opinions verbally without the limitations that some might find in giving a written response. This was evident in the depth of the discussions triggered by these focus groups and in the kind of issues raised by the participants. These discussions were also valuable in providing many language-use examples and several suggestions and recommendations connected to the research topic.

\section{Procedures}

All participants were informed about the nature of this study, and all consented to the anonymous use of their data. The questionnaire dissemination resulted in 97 completed returned responses. The focus groups meeting's objectives were also explained to the participants along with the research questions, and the researcher recorded the discussion with the consent of the participants. The researcher conducted the focus groups in a discussion-panel format, using a video conferencing technology. Both the questionnaire and the focus groups data were analyzed using qualitative content analysis in accordance with Mayring (2014).

\section{Results}

\section{Students' Perspective on Teaching Culture}

In the first dimension of this study, the discussions focused on the extent of the disconnection from the target culture in the language teaching process as experienced by the participants in this research. In their response to the first item in the questionnaire, the participants were unanimous in expressing their concern over the lack of a cultural perspective in many of the EFL courses in 
their academic plan. Students stated that missing the cultural background of certain words and topics encountered in their studies had affected their understanding of the language and had resulted in many cases of erroneous translations and failed communications. Specifically, many students indicated that this issue started at the end of the language skills phase of the program and with the commencement of the linguistics and translation phase. During this period, students usually begin dealing with more advanced texts and culturally focused audiovisual materials connected to the advanced courses in their program. The participants indicated that at this stage, students come across many concepts that are not found in the local culture (as illustrated in the next section) and that are vital to the process of understanding the meaning in many instances that involve comprehension, communication, or translation.

Students described the problem of language and culture in their curriculum by dividing it into two categories. The first involved the informal contexts of language that require a substantial knowledge of the cultural concepts and paradigms that are part of English-speaking societies. This challenge is manifested in the errors students make when dealing with issues that native speakers experience in their daily lives but are not connected to a specific serious/academic discipline or field of work. These include, for example, terms that are part of certain slangs, local dialects, nonstandard vernaculars, and sports metaphors, in addition to language features associated with certain subcultures.

The second area is connected to the cultural information embedded in many serious and formal fields and associated with several occupational and topical registers, jargon words, and idiomatic expressions. Thus, the culturally bound terminology in fields like politics, business, and media production has proven to be highly challenging to many students. It is worth noting here that these fields have dedicated translation courses in the English program offered by COLT. In these contexts, participants indicated that focusing on the textbook's terminology only, without engaging with the cultural aspects of these fields, would not be enough to achieve a satisfactory level of linguistic/sociolinguistic competence.

\section{Language-Use Examples}

In this section, the language-use examples that illustrate the difficulties associated with teaching culture in the language classroom can be categorized into three types: field-specific cultural terms and expressions, cultural concepts that are foreign to students, and culture-specific general words and idiomatic expressions. In the first category, students reported several communication and translation errors that resulted from encountering culture-specific terms and phrases connected to particular disciplines. For example, in the field of politics, the culturallybased names of specific positions and institutions may cause some difficulties for EFL students who do not have access to the cultural aspects of the English language. Specifically, the participants reported misunderstanding terms such as "secretary of state" and "home office" while working on specialized texts as part of their curriculum tasks. In both examples, students indicated that they adopted the literal sense of these terms, which alters their meaning and usage. In the first example, "secretary" was understood as "personal assistant" rather than "cabinet minister". In the second example, "home" was understood as "resident" and not as "interior," while "office" was understood as "desk" rather than "ministry." Students were familiar with the terms "minister of foreign affairs" and "minister of interior", but were not familiar with the alternative terms because of their limited exposure to the cultures that use these terms. The 
participants also reported having difficulties recognizing the position of "chancellor of the exchequer" (used in the British political culture), even though the same students knew the alternative, "minister of treasury."

In the field of business, the participants raised the issue of recognizing specific terms and expressions that are connected to the business culture in the English language but have basic and better-known alternatives. For example, in the questionnaire, students talked about the expression "chapter 11," which is mainly used to describe certain bankruptcy cases in the American culture. Even though the term "bankruptcy" was not new to students, they failed to connect it to the more culture-specific term, "chapter 11." In another example, students reported having difficulties understanding the term "golden parachute," used to describe certain types of severance pay for company executives. The literal meaning of this expression was misleading to many students, and a more focused search was needed to allow them to use the term correctly. Additionally, the concept of "bucking the trend" in the stock market was well known to the students in the sample but not the expression itself. The various meanings and the different parts of speech connected to the word "buck" created much of the misunderstanding. The term "downsize" (with the meaning of reducing the number of employees by terminating employment) was also one of the business expressions that were challenging to students when dealing with texts from that field.

In the questionnaire, the students reported misunderstanding several words and phrases that can be categorized as part of the media (or media production) terminology. For example, the term "autocue" (a device that projects scripts for television presenters) was understood based on the meanings of "auto" (connected to cars) and "cue" (line). In another instance, the term "pilot" (used in media production to mean a one-off episode in a proposed series) was very challenging for students, even when provided in context, as it was confused with the more general meaning of "aviator." In the area of political TV shows, the term "spin" (associated with propaganda and giving biased opinions) was cited as an example of the terms that can be misleading if viewed in disconnection from their cultural context.

The second category in this analysis includes the concepts that are not found in the students' local society and with which they are not closely familiar, like Halloween. In the questionnaire, a participant provided the example of not identifying the expression "trick or treat," which is part of the Halloween tradition. This celebration (which is not part of the local culture) might be known in the society to a certain extent, but the terms used in relation to it are less common. Specifically, the use of "trick or treat" as a verb with an "ing" ending caused the misunderstanding for a participant because, in reality, it is not practiced by the members of the speech society in which he lives. Other cultural concepts have also created difficulties for many language learners, because of their absence from (or relative rarity in) the local culture, including "going Dutch" (within a group, each paying for their own meal in a restaurant) and "prenuptial" (a financial agreement before marriage).

In the third category, the participants provided several examples of culture-specific general terms and idiomatic expressions that cannot be translated or understood in their literal sense. The examples illustrate the significance of realizing the cultural contexts when learning new vocabulary in a foreign language. All the examples given by the participants in the following list 
contain expressions with fixed uses that cannot be figured out by knowing the individual meaning of the words in them. These include:

spill the beans, bite the bullet, the cold shoulder, cold feet, feeling blue, long face, cat got your tongue, break a leg, cook the books, pie in the sky, call shotgun, break the ice, pull someone's leg, couch potato, hot air, go bananas, be high, cut corners, beat (exhausted), jumper (jacket), wheels (a car), beat around the bush, a heads-up (a warning), by hook or by crook, don't sweat it, wicked (British slang: wonderful), willy-nilly, through thick and thin, face the music, lit (drunk or exciting), busted (discovered), rat (snitch), dig (American slang: understand), dough (American slang: money), crash (sleep), a screwup (loser)

Using the literal meaning of these terms and expressions created enormous difficulties for students and resulted in communication breakdowns and translation mistakes. The participants indicated that introducing students to this kind of language at an earlier stage of their studies would have given them a better chance of dealing with texts and conversations that involve such culture-specific terminology. The preceding list is not exhaustive; however, the goal of including it is to illustrate the type of expressions with which students struggle in both the EFL skills and the translation classrooms. A more comprehensive list can be created in any future attempt to produce teaching materials or glossaries that aim to introduce students to culture-specific terms, which is a topic that will be discussed in the next section. Nonetheless, it was essential to include these examples in this analysis because this aspect was one of the key features missing from many of the previous studies in this field within the Arab World.

\section{Discussion}

The results revealed that the disconnection between language and culture in the Saudi EFL classroom is real and that it is negatively impacting students' ability to achieve their language proficiency objectives. The results also show that culture-specific words and concepts emerge as the most affected aspect of language in the cases where cultural knowledge is excluded from language teaching.

There are several approaches that can be taken to help students overcome the difficulties associated with culture-specific terms and expressions. Some of these suggestions were provided by the participants in the questionnaire and the focus groups as part of their response to the discussion points raised by the researcher. These suggestions, however, will be assessed and restructured based on the practicality and feasibility considerations. Other suggestions will be provided by the researcher based on previous successful experiences in teaching both EFL and translation courses and in studying and training in similar situations in English-speaking societies. These suggestions will also be viewed in light of the most recent research on this topic, taking into consideration the differences in the social and linguistic contexts.

One of the main issues raised in the focus group discussions and the questionnaires was the lack of real-life opportunities for students to communicate with native speakers of the English language. The goal is not only to improve the students' language skills but also to introduce them to aspects of the foreign language culture that can only be found in real-life conversations with representatives of that culture. In previous years, the COLT program organized a "twinning 
program" that allowed students to spend a year in an English-speaking country to study courses that could then be counted toward the total number of hours required for graduation. However, the program's contract was not renewed in later years, which resulted in the loss of a significant opportunity for students to acquire language skills and to learn more about the target language culture. Nonetheless, there are some recent developments that can be extremely helpful in this regard, thanks to the use of modern technology and the help of professional academic networks.

In the past two years, a period in which students have depended mainly on online education, the use of video conferencing applications has become highly accessible, and students are now more accustomed to this method of teaching and communication. At the same time, many of the lecturers working at COLT (and in other EFL programs in Saudi Arabia in general) have graduated with higher degrees from international universities in English-speaking countries around the world. Those lecturers maintain consistent research and professional connections with other academics in these international institutions. The suggestion is to organize online cultural discussions between EFL students and other students who are native speakers of English in these international universities. The goal is to provide an authentic cultural experience for both groups in a way that can be academically beneficial to all participants in these discussions. The EFL students will have the chance to gain actual exposure to native speakers using real/everyday language and discuss topics that can offer a window into the culture of the foreign language they are learning. The students in the international universities can receive credits for participating in these discussions as part of their tasks in the sociolinguistics or the language and culture courses.

Another point emphasized by the participants in the focus groups and the questionnaire was the significant benefits gained from enrolling in two specific courses in their program and the need for maximizing the scope and length of these courses. In the fifth and sixth levels of COLT's English program, students are enrolled in two courses titled Readings in Language and Culture and Advanced Readings in Language and Culture. In these courses, students are introduced to several aspects of the cultural context of English, specifically those connected to language. Thus, the courses would usually focus on topics such as accents, dialects, registers, jargon, slang, vernaculars (e.g., African American English), and language and gender. The participants emphasized the importance of these courses and the extent of the cultural knowledge that students can receive by enrolling in them. However, the participants indicated that the scope of these courses should be expanded to cover other aspects of culture connected to the English language. They also stated that the time allocated for these courses (two hours a week) should be extended to at least three hours a week. This request can be highly effective in this regard because it would allow instructors to provide more detailed examples of the discussed topics and would give students the opportunity to share, with their colleagues, the findings of their own research and expanded readings on the topics assigned to them in these courses. The additional focus on these courses is not expected to cover all aspects of culture, but the goal is to introduce students to the cultural topics that can influence language. Students can then expand their knowledge independently by exploring the broader expanse of these topics in a way that would allow them, for example, to learn more about the differences between the English language dialects; the various registers, slangs, and vernaculars; and the influence of gender on the use of language. 
Another suggestion from which students can benefit immensely is the creation of language culture clubs in EFL departments. The objective of these clubs is to institutionalize the efforts to introduce students to the cultural aspects of the foreign language they are learning and provide venues (either actual or virtual) in which they can participate in cultural activities with a focus on language. Students who have shared interests in language and culture can attend these clubs and organize events that are aimed at improving students' awareness of culture-specific terms and concepts. The activities in these clubs can include watching documentaries about language and culture and then holding discussion panels on the content to allow students to comment on and review the themes included in these films. In the questionnaire, students raised the issue of knowing extremely little about dialects such as Irish and Scottish; thus, the use of documentaries can be one of the ways to deal with this issue and improve students' knowledge of these dialects and cultures. The language culture clubs can also organize contests and virtual reality games with particular emphasis on the cultural objectives of these clubs. Additionally, the students can also choose books about language and culture topics and meet periodically to talk about these issues and share and discuss the information they have learned from these books.

Finally, students should be encouraged to adopt self-learning approaches that focus on the specific fields and areas in which they faced difficulties with regard to the language culture and the jargon terms of these fields. For example, instructors should inform students about the most suitable audiovisual materials and texts that cover fields like politics, business, legal practice, and the military, which are areas known to involve special registers and technical cultural jargon. Thus, students can be encouraged to watch certain political programs, listen to specific legal podcasts for non-specialists, read the business pages of English newspapers (usually involving a large amount of business culture terminology), and watch military service shows and documentaries that include the most common military culture words.

\section{Conclusion}

The disconnection between language and culture in EFL situations in the Saudi context is evident in many cases. Language instructors can clearly observe the consequences of this disconnection as it affects their students' proficiency, comprehension and translation accuracy. The aim of this paper is to illustrate the extent to which cultural knowledge is missing from EFL classrooms at the university level in this region. This study has also documented many of the language use examples that demonstrate the difficulties faced by students in this context. This aspect can help in determining the scope of the problem and can be part of the solution (e.g., the creation of cultural terms glossaries). Language use examples have always been missing from many of the studies on this topic in the local Arab context.

This study confirmed the extent of the difficulties faced by students in the area of language and culture and provided the basis for several recommendations and suggested solutions that can help improve students' realization of the cultural features of the foreign language they are learning. The solutions to the lack of cultural content in the EFL classroom can differ from one society to another, depending on the available resources and existing opportunities. Thus, in the Saudi context, certain factors can have an extremely positive impact on the efforts to rectify the language culture issue. These factors include the strong professional academic connections between the teaching staff in local institutions and in many international universities, which can result in successful cooperation in this regard, the expansion in adopting virtual classrooms and 
online learning during the past two years, and the existence of dedicated language and culture courses that can be further developed and improved. The academic leadership in Saudi EFL programs can also be influential in supporting the creation of language culture clubs, with the availability of the needed logistics and financial resources in local Saudi institutions. These suggested solutions can also be applied to other programs that have the same circumstances with regard to students' needs and institutional capabilities.

For future studies, it is recommended that further research is conducted to examine the difficulties facing EFL students in the field of language culture by utilizing the language use example in this current study to compare the local Saudi EFL case with other cases in different societies and linguistic contexts. This can be done, for example, by incorporating these culturespecific terms and expressions in placement tests to determine the extent of the language culture difficulties found in other institutions. The language use examples can also be utilized in creating a dynamic glossary for cultural terms that can be uploaded to a website and expanded regularly to include the new expressions that emerge within the target language culture. This glossary and other similar resources can then be used to increase EFL students' awareness of the cultural aspects of the foreign language they are learning. It is hoped that the suggested solutions and the findings of this research can be part of the discussion on the issue of language culture difficulties for EFL students and be a clear manifestation of the situation in local Saudi English programs.

\section{About the Author:}

Abdullah Bin Towairesh obtained his PhD in Linguistics from The University of Queensland, Australia. He authored two book chapters on 'Addressing Strangers in Riyadh' and on 'Saudi Contributions to Translation in the Field of Linguistics.' He also translated the licensed Arabic version of David Crystal's book 'Internet Linguistics.' His most recent publication is 'Language Ideologies and Saudi Society: Understanding the Concept of Diglossia.' He is currently an Assistant Professor of Linguistics at King Saud University's College of Languages and Translation. ORCID: https://orcid.org/0000-0003-2611-1887

\section{Reference}

Aldawood, A. A., \& Almeshari, F. (2019). Effects of learning culture on English-language learning for Saudi EFL students. Arab World English Journal, 10(3), 330-343. https://dx.doi.org/10.24093/awej/vol10no3.23

Alsamani, A. (2014). Foreign culture awareness needs of Saudi English language majors at Buraydah Community College. English Language Teaching, 7(6), 143-153. https://doi.org/10.5539/elt.v7n6p143

Alseghayer, K. (2009, July 19). Teaching the English language in disconnection from culture. Al Jazirah Newspaper, Issue 13443. www.al-jazirah.com/2009/20090719/ar5.htm

Bagui, H., \& Adder, F. Z. (2020). Promoting students' intercultural communicative competence through English literary texts: Students' attitudes and teachers' challenges. Arab World English Journal (AWEJ), 11(2), 85-93. https://dx.doi.org/10.24093/awej/vol11no2.7

Baker, W. (2012). From cultural awareness to intercultural awareness: Culture in ELT. ELT Journal, 66(1), 62-70. https://doi.org/10.1093/elt/ccr017 
Bayyurt, Y. (2006). Non-native English language teachers' perspective on culture in English as a foreign language classroom. Teacher Development, 10(2), 233-

247. https://doi.org/10.1080/13664530600773366

Choudhury, M. (2013). Teaching culture in EFL: Implications, challenges, and strategies. IOSR Journal of Humanities and Social Science, 13(1), 20-24. https://doi.org/10.9790/08371312024

Dema, O., \& Möller, A. (2012). Teaching culture in the 21st-century language classroom. In T. Sildus (Ed.), Touch the world: Selected papers from the 2012 Central States Conference on the Teaching of Foreign Languages (pp. 75-91). Crown Prints.

Goodwin, R. (2013). A discussion on teaching a language without teaching its culture. Arab World English Journal, 4(4), 60-77.

Hamza, A. A. (2018). The role of culture in teaching and learning English as a foreign language. Basic Education College Journal of Education and Humanities Sciences, April, 797-807.

Jeeyoung Shin, Zohreh R. Eslami \& Wen-Chun Chen (2011) Presentation of local and international culture in current international English-language teaching textbooks, Language, Culture and Curriculum, 24:3, 253-268, DOI: 10.1080/07908318.2011.614694

Kachru, B. (1992). The other tongue: English across cultures. University of Illinois Press.

Kramsch, C. (1993). Context and culture in language teaching. Oxford University Press.

Larzén-Östermark, E. (2008). The intercultural dimension in EFL teaching: A study of conceptions among Finland Swedish comprehensive school teachers. Scandinavian Journal of Educational Research, 52(5), 527-547. https://doi.org/10.1080/00313830802346405

Lavrenteva, E., \& Orland-Barak, L. (2020). Teaching culture in the EFL classroom as informed by teachers' approaches to student diversity. Research Papers in Education. Available at https://doi.org/10.1080/02671522.2020.1864763

Mayring, P. (2014). Qualitative content analysis: Theoretical foundation, basic procedures, and software solution. Klagenfurt. Available at http://nbn-resolving.de/urn:nbn:de:0168-ssoar$\underline{395173}$

Mekheimer, M. A. A., \& Aldosari, H. S. (2011). Impediments to cultural teaching in EFL programs at a Saudi university. Journal of Intercultural Communication. Available at https://www.immi.se/intercultural/nr26/mekheimer.htm.

Newmark, P. (2010). Translation and culture. In B. Lewandowska-Tomaszczyk, \& M. Thelen (Eds.), Łódź studies in language (pp. 171-182). Peter Lang GmbH.

Shamail, A. (2015). The nexus of language and culture in foreign language education. TESOL Arabia Perspectives, 23(1), 18-23.

Shin, J., Eslami, Z. R., \& Chen, W.-C. (2011). Presentation of local and international culture in current international English-language teaching textbooks, Language, Culture and Curriculum, 24(3), 253-268. https://doi.org/10.1080/07908318.2011.614694

Singhal, M. (1997). The Internet and foreign language education: Benefits and challenges. The Internet TESL Journal, 3(6). Available at http://iteslj.org/Articles/Singhal-Internet.html

Yeşil, Ş., \& Demiröz, H. (2017). An exploration of English language teachers' perceptions of culture teaching and its effects on students' motivation. International Journal of Progressive Education, 13(1), 79-95. https://ijpe.penpublishing.net/makale/226. 